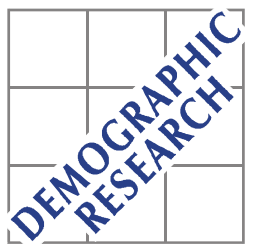

Demographic Research a free, expedited, online journal of peer-reviewed research and commentary in the population sciences published by the Max Planck Institute for Demographic Research Konrad-Zuse Str. 1, D-18057 Rostock · GERMANY www.demographic-research.org

DEMOGRAPHIC RESEARCH

VOLUME 14, ARTICLE 20, PAGES 485-508

PUBLISHED 02 JUNE 2006

http://www.demographic-research.org/Volumes/Vol14/20/

DOI: 10.4054/DemRes.2006.14.20

Research Article

The community-level effects of women's education on reproductive behavior in rural Ghana

Kofi D. Benefo

(c) 2006 Max-Planck-Gesellschaft. 


\section{Table of Contents}

$1 \quad$ Introduction 486

1.1 Theory and literature review 486

2 Setting, data, variables, and measurement 488

$2.1 \quad$ Setting and data $\quad 488$

$2.2 \quad$ Variables and measurement $\quad 489$

2.2.1 Dependent variables $\quad 489$

2.2.2 Independent variables $\quad 491$

Individual-level variables $\quad 491$

Community level variables $\quad 492$

3 Analyses 493

3.1 Preliminary results 493

3.2 Multivariate analytical technique 494

3.3 Multivariate results 495

3.3.1 Interest in regulating fertility 495

$\begin{array}{lll}3.3 .2 & \text { Contraceptive use } & 498\end{array}$

$4 \quad$ Discussion and conclusion $\quad 500$

$\begin{array}{ll}\text { References } & 503\end{array}$ 


\title{
The community-level effects of women's education on reproductive behavior in rural Ghana
}

\author{
Kofi D. Benefo ${ }^{1}$
}

\begin{abstract}
Using survey data collected in rural Ghana during the 1980s, this study examines whether a woman's interest in fertility regulation and contraception is influenced by the education of other women in her community. The study finds that, net of her own characteristics, a woman's interest in limiting fertility and using modern contraception increases with the percent of women with education in her community. The finding suggests that female education has a greater capacity to introduce novel reproductive ideas and behaviors into rural areas of Africa and thereby transform the demographic landscape in the region than is currently believed. Other community characteristics that increase women's interest in regulating fertility and contraceptive use in this setting include access to transportation and proximity to urban areas. However, these are not as powerful as women's education in transforming reproductive behavior.
\end{abstract}

${ }^{1}$ Ph.D., Dept. of Sociology and Social Work, Lehman College, CUNY, 21 Oakey Drive, Kendall Park, New Jersey 08824.
E-mail: kofi.benefo@lehman.cuny.edu 


\section{Introduction}

Women's education occupies a unique place in demographic discourse and policy because a large amount of empirical research has revealed that educated women delay marriage, use contraceptives, reduce fertility and produce many other beneficial reproductive and child health outcomes (United Nations 1991). In recent years, new research showing that a woman's schooling affects the reproductive and health behaviors of other women has raised the possibility that female education has greater capacity to transform the demographic landscape of a society than is currently believed (Kravdal 2002). This study contributes to this new research on women's education by examining whether a rural Ghanaian woman's interest in regulating her fertility and using contraception is influenced by the schooling of other women in her community. It pursues the analysis by looking at the relationships between the average education of women in a community and an individual woman's interest in fertility regulation and contraceptive use while controlling for her education and other socio-economic and demographic characteristics.

In the next section, the paper reviews theories and research literature elucidating how the average education of women in a community affects the reproductive behavior of individual women. It also identifies community and individual-level characteristics used as controls in the multivariate analyses. The paper then goes on to provide background demographic information on Ghana and to describe the data, variables and measures employed for the analyses. The analyses section reviews the multilevel modeling methods employed to estimate community-level influences on reproductive behavior and the results of the multivariate analyses. The conclusion discusses the study's implications for population policy and research.

\subsection{Theory and literature review}

There are a number of reasons why demographers believe a woman's reproductive behavior can be influenced by the education of other women. Diffusion theories emphasize the role of elite educated women in exposing other women to new ideas about fertility control. According to the theories, elite educated women develop a heightened awareness of the opportunity costs of childbearing, learn about western contraception and become empowered to adopt them (Johnson-Hanks 2003 2-3). These elite women then act as sources of information, social support and social pressure that diffuse their new lifestyles and ideas to other women (Montgomery and Casterline 1996; McNay, Arokiasamy and Cassen 2003). 
Other theories argue that the education of women in a community changes the institutional setting in ways that reduce the incentive to have many children. Some claim that the education of some women in a community initiates social and ideational changes that undermine traditional patriarchal power and reduce men's interest in having large numbers of children as it becomes difficult for them to devolve the costs of childbearing onto their wives (McNay et al. 2003). Other versions of institutional theory suggest that women's education makes female labor markets more competitive or increases women's interest in educating their children. These social changes give rise to the idea that social mobility is incompatible with large family sizes (Kravdal 2002). However it happens, these theories imply that individual women become interested in regulating their fertility and using contraception as other women in their community become educated.

A number of empirical studies support the claim that the presence of educated women in a community is associated with reduced fertility for women, regardless of their individual characteristics. Net of a woman's own education, the average education of women in a community has been shown to have a negative association with individual fertility in Peru (Tienda, Diaz and Smith 1985), Thailand, Malaysia, Indonesia and the Philippines (Hirschman and Guest 1990; Hirschman and Young 2000), Kenya (Lesthaeghe et al. 1985), sub-Saharan Africa (Kravdal 2002) and South India (Morsound and Kravdal (2003). In Bangladesh (Amin, Diamond and Steele 1996), India (McNay et al. 2003) and Zimbabwe (Kravdal 2000) researchers found positive associations between community level literacy among women and individuallevel contraceptive use, net of an individual woman's schooling.

Although most available research on the issue indicates that the average education of women in a community usually increases a woman's interest in contraception and regulating fertility and reduces her fertility, some studies suggest that the relationship is much more complicated. This research suggests that the average education of women could lead to increases in fertility by undermining interest in certain methods of fertility regulation. For instance, in Kenya, Lesthaeghe et al. (1985) found that, net of an individual women's schooling, aggregate education of women in a community was negatively associated with the length of breast-feeding and post-partum abstinence. Breast-feeding and post-partum abstinence are not methods for regulating family size, nevertheless, as they are reproductive strategies that have a long history in Africa, their reduction with increases in the aggregate education of women raises the possibility that methods of regulating fertility that are traditional to Africa, such as birth-spacing and traditional contraceptives, are likely also to be reduced (Lesthaeghe 1984). To deal with the complicated relationship between education and fertility hinted at by Lesthaeghe et al. (1985), this study distinguishes education's impact on interest in birth-spacing and using traditional contraception, practices known to be culturally traditional to rural 
Ghana (Bleek 1987; Ghana Ministry of Health 1992) from its effect on interest in limiting childbearing and using modern contraception, practices demographers view as critical to initiating fertility transitions (Van de Walle and Knodel 1980).

Three community characteristics believed to influence fertility are controlled to prevent them from confounding estimates of female education's aggregate effects (Kravdal 2000, 2002; Moursund and Kravdal 2003). One is proximity to urban areas because historically ideas supporting low fertility diffused from urban to rural areas through migratory processes (Brockerhoff 1995; Goldscheider 1984; Kravdal 2000, 2002; Gugler and Flanagan 1978; Reed, Briere and Casterline 1999; Saha 1994; Shapiro and Tambashe 2001). The second is community access to transportation. In Bangladesh (Ahmed 1994; Saha 1994) and some parts of Africa (Hammerslough 1992; Reed et al. 1999), ideas and behaviors that support interest in regulating fertility and using contraception appear to arrive in a community through its communication linkages with the outside world. The third is community infrastructural development because access to modern amenities like electricity, farming machinery and health services have the potential to reduce economic and social uncertainty in a community and thereby turn the economic calculus against high fertility (Caldwell and Caldwell 1985; Entwisle, Casterline and Sayed 1989; Harbinson and Robinson 1985; Saha 1994).

Also included in the analyses as controls are eight individual characteristics of women shown to influence reproductive behavior. Five of them are indicators of a woman's socioeconomic status such as her education and nonfamilial work status (Mason 1987), her exposure to family planning information and the mass media (Bankole, Rodriguez and Westoff 1995; Easterlin and Crimmins 1985; Freedman 1997; Westoff 1999; Westoff and Rodriguez 1995), as well as her membership of privileged ethnic and religious networks (Raftery, Lewis and Aghajanian 1995; Watkins 1991). Three are indicators of life-cycle stage, a woman's family size, age and age at first marriage (Hirschman 1985; Kocher 1979; Malhotra and Thapa 1991).

\section{Setting, data, variables, and measurement}

\subsection{Setting and data}

Ghana is at the initial stages of a fertility decline. Between 1988 and 1998, total fertility rates declined from 6.4 to 4.6. Urban rates went from 5.3 in 1988 to 3 in 1998 while rates in rural areas went from 7 to 5.3 (Lloyd, Kaufman and Hewet 2000; Ghana Statistical Service 1989; Onuoha and Timaeus 1995). Changes in sexual behavior and increases in the use of contraception have been important in accounting for the fertility decline. In urban areas, contraceptive prevalence rates for currently married women 15- 
49 years went from $9.5 \%$ in 1979 to $20.3 \%$ in 1998 while in rural areas they went up from $9.9 \%$ to $18.1 \%$ (Lloyd et al. 2000; Ghana Statistical Service 1989; Onuoha and Timaeus 1995).

Although much is known about the proximate determinants underlying fertility decline in Ghana, little is known about the socio-economic factors that have accounted for the changes in attitudes towards family size and contraception. By examining the role of women's education, this study may be helpful in pinpointing the socioeconomic roots of fertility decline in the region. The study focuses on the period surrounding the decline's start in the 1980s, before it became widespread and obscured the socioeconomic differentials that initially were the source of fertility change. The study sample is obtained from the 1988 Ghana Demographic and Health survey (DHS) of 4,488 women aged between 15 and 49 years conducted by Macro International, Inc. and the Ghana Statistical Service (Ghana Statistical Service 1989). The DHS survey data are supplemented with other data from the 1984 Ghana population census (Government of Ghana 1984) and 1987 and 1988 Ghana Living Standard Surveys (Government of Ghana 1987, 1988)

Of the women surveyed in the 1988 Ghana DHS, only 2,965 lived in rural communities with fewer than 5,000 people. Unmarried respondents were eliminated to arrive at 2,195 currently married women. An additional seventy-five women who selfreported as infecund were excluded, along with respondents lacking information on some study variables, to leave the study sample size at 1,812 currently married women residing in 63 rural and semi-urban communities with populations not exceeding 5000. Sample attrition resulting from missing values appears not to be a problem - a comparison of the sample of all currently married women with the study sample on a number of socio-demographic characteristics showed them to be virtually identical.

\subsection{Variables and measurement}

\subsubsection{Dependent variables}

The two dependent variables, listed in panel A of Table 1, are operationalized with data from the Ghana DHS. 
Benefo: The community-level effects of women's education on reproductive behavior in rural Ghana

\section{Table 1: Variables, measures and univariate statistics}

\begin{tabular}{|c|c|c|c|}
\hline \multirow[t]{2}{*}{ Variable Names } & \multirow[t]{2}{*}{ Measures } & \multicolumn{2}{|c|}{ Univariate Statistics } \\
\hline & & Means & Range \\
\hline \multicolumn{4}{|l|}{ A. Interest in Fertility Regulation } \\
\hline 1. Desire no more children (LIMIT) & & 0.20 & $0-1$ \\
\hline 2. Desire more after 2 years (SPACE) & & 0.48 & $0-1$ \\
\hline 3. Desire now/uncertain (NOW) & & 0.32 & $0-1$ \\
\hline \multicolumn{4}{|l|}{ B. Contraceptive use } \\
\hline 1. Modern methods (MODERN) & & 0.03 & $0-1$ \\
\hline 2. Traditional methods (TRAD) & & 0.06 & $0-1$ \\
\hline 3. Intend to use (INTEND) & & 0.29 & $0-1$ \\
\hline 4. Not using/Not Intending (NONUSE) & & 0.62 & $0-1$ \\
\hline \multicolumn{4}{|c|}{ B. Individual-Level Independent Variables } \\
\hline Woman's exposure to family planning ads. & has seen/heard family planning ads. & 0.08 & $0-1$ \\
\hline Woman's Ga-adangbe/Ewe ethnicity & is Gaadangbe or Ewe & 0.27 & $0-1$ \\
\hline Woman's non-animist religion & is not a traditional African religionist & 0.86 & $0-1$ \\
\hline Woman's schooling & has some schooling & 0.45 & $0-1$ \\
\hline Woman's work & works in enterprise not owned by family member & 0.48 & $0-1$ \\
\hline Woman's age at 1 st marriage & age at first marriage & 17.6 & $8-41$ \\
\hline Woman's age & completed years & 31.00 & $16-49$ \\
\hline Woman's family size & number of surviving children & 3.32 & $0-12$ \\
\hline \multicolumn{4}{|c|}{ C. Community-Level Independent Variables } \\
\hline Aggregate women's education & $\begin{array}{l}\% \text { of women } 15-49 \text { yrs with any formal } \\
\text { schooling in sampling cluster }\end{array}$ & 52.52 & $0-92.59$ \\
\hline \multicolumn{4}{|l|}{ Community transportation: } \\
\hline 1) Public transportation & $\begin{array}{l}\text { 1) Sampling cluster has public transportation \& } \\
\text { motorable road }\end{array}$ & 0.57 & $0-1$ \\
\hline 2) Motorable road & 2) Sampling cluster has motorable road only & 0.22 & $0-1$ \\
\hline 3) No transportation & 3) Sampling cluster had no motorable road & 0.21 & $0-1$ \\
\hline Urbanization & $\begin{array}{l}\% \text { of district's population in towns with at least } \\
10,000 \text { people }\end{array}$ & 8.35 & $0-49.92$ \\
\hline Community infrastructure development & see text for description of index & 4.55 & $0-14$ \\
\hline
\end{tabular}


Women's interest in regulating their future childbearing is assessed with a categorical variable that distinguished limiters who wanted to stop childbearing at the time of the survey (LIMIT) because most researchers see limiting childbearing as the prime motivator of modern day fertility declines. It also distinguished spacers who wanted to delay the next child by at least two years (SPACE) because spacing is fertility-regulating behavior that is traditional to rural Ghana. The third category included people who wanted children within two years of the survey, or wanted children but were unsure of the timing together with those who were undecided about their plans for childbearing (NOW). People in the third category were assumed to be uninterested in regulating their family size.

The second dependent variable, interest in using contraception, distinguished modern contraceptors (MODERN) using high technology, biomedically efficient contraceptives such as pills, IUDs, injections, diaphragm/foam/jelly, condoms, female sterilization, male sterilization, and Norplant. It also distinguished traditional contraceptors (TRADITIONAL) whose low technology and behavioral methods, including periodic abstinence, rhythm, withdrawal, herbs and potions, represent reproductive strategies that have some history in rural Ghana. A third category of the variable distinguished women who were not using any method at the time of the survey but expressed an intention to do so in the future (INTEND) while the fourth category included women who expressed no interest in using contraception and were not using any at the time of the survey (NOT).

\subsubsection{Independent variables}

\subsubsection{Individual-level variables}

Measures of the individual-level independent variables are described in panel B of table 1. The data on which they are operationalized come from the 1988 Ghana DHS. The measure for a woman's schooling distinguished women with any schooling from others. The measures for nonfamily work and the family planning exposure variables distinguished women who are nonfamily employees and those who have seen commercials about family planning from other women. The respondent's ethnic network measure distinguished Gaadangbe-ewes from members of other ethnic groups because the former, located in southern coastal areas of Ghana, have experienced more westernization and socio-economic development than the latter. For the same reason, the measure for religious networks distinguished non-animists who have more exposure to westernization and development, from adherents of traditional African religions. 
Measures for the life-cycle variables, family size, age, and age at marriage, are described in table 1 .

\subsubsection{Community level variables}

The key independent variable, the aggregate education of all women in a community, is operationalized as the percent of reproductive aged women in a sample cluster with any schooling and is based on data from the DHS. The measure of proximity to an urban area is operationalized as the percent of a district's population in communities with over 10,000 inhabitants, using data from the 1984 Ghana population census. The three category community transportation measure distinguished sampling clusters with motorable roads and public transportation, those with motorable roads only, and a third group with neither motorable roads nor public transportation. Community infrastructural development is operationalized as the number of the following 17 services and facilities available in a sampling cluster; close proximity to an agricultural extension center, hospital, clinic, pharmacy, maternity home, farmer's cooperative society, cooperative societies, pipe born water in most homes, bar, restaurant or other outdoor eating facility, post office or public telephone, bank, adult literacy program, electricity in most homes, primary, middle or secondary school, and a permanent market. The last two community measures utilized information from the 1988 Ghana Living Standard Survey that was provided by community leaders.

The community predictors described above represent only a small portion of the community-level characteristics examined in this study. Many other variables were examined but were excluded from the final models because of constraints posed by community sample size. In multilevel analysis, the rule of thumb is that there should be at least ten communities per community-level predictor in the model (Raudenbush and Bryk, 2002). The moderate number of communities (63) available for this study meant that some potentially important variables had to be left out of the final models. For instance, village access to family planning services was excluded from the final models in part because of the constraints posed by the community sample size. Analyses with a family planning variable showed it to have some association with reproductive behavior. Net of a whole host of socio-economic characteristics, a woman's interest in limiting family size, but not in spacing children, using or intending to use contraception increased in communities within five miles of a family planning clinic or worker. However, that result had to be weighed against research showing the placement of family planning services to be a nonrandom process in many developing countries (Gustavo, Guilkey and Mroz 1988). I could not discount the possibility of bias in my

estimates of family planning service effects arising from nonrandomness in service 
placement. For that reason, it made sense, given the constraints posed by the relatively small number of communities available for the study, to leave the family planning variable out of my final models.

\section{Analyses}

\subsection{Preliminary results}

Preliminary statistics on the dependent variables presented in table 1 reveal that many women were interested in regulating their family in 1980s rural Ghana. While 32\% of women wanted a child at the time of the survey (NOW), $20 \%$ of currently married women wanted to stop childbearing (LIMIT) and $48 \%$ desired to delay the next child by at least two years (SPACE). In striking contrast to the large number of women interested in regulating their families, the statistics on the contraceptive use variable indicate that few people were using contraception. Only 3\% of currently married women were using modern contraceptives (MODERN) and 6\% were using traditional methods (TRAD). At 29\%, the percent of currently married women who intended to use contraceptives is much larger than the $9 \%$ actually using, but is still much less than one would expect given the large number of women who expressed an interest in regulating fertility.

The community-level statistics in panel $\mathrm{C}$ of Table 1 show rural Ghana to be a fairly underdeveloped setting with limited education of women, limited urbanization and limited development. The average community had only about $53 \%$ of women in the reproductive ages with any schooling, was located in a district with only $8 \%$ of its population in urban centers, and had only between four and five of 17 possible development infrastructures. The country does have a reasonably well-developed transportation system. Only $21 \%$ of communities have no access to motorable roads at all. About $57 \%$ of communities have public transportation and motorable roads while $22 \%$ have motorable roads only.

As the setting is poor, women's education offers considerable promise for promoting fertility decline if it can be shown that interest in regulating fertility and using contraception increases with their aggregate education. The next section describes the multivariate analyses examining that issue as well as the closely related, but more general issue of how important community characteristics are as determinants of women's interest in fertility regulation and contraception. 


\subsection{Multivariate analytical technique}

I employed multinomial logit modeling for the multivariate analysis. Multinomial logit regression, depicted generally as,

$\log \left(\mathrm{P}_{\mathrm{i}} / \mathrm{P}_{\mathrm{m}}\right)=\mathbf{X b}$,

models the "log of the odds" of being in category ' $\mathrm{i}$ ' relative to category ' $\mathrm{m}$ ' of a dependent variable as a function of $\mathbf{X}$, a matrix of independent variables, and ' $\mathbf{b}$ ', a column vector of unknown parameters (Maddala 1983). Once estimated, the components of $\mathbf{b}$, known as logit coefficients, depict changes in the logits of making choice ' $\mathrm{i}$ ' rather than choice ' $\mathrm{m}$ ' on the dependent variable in response to increases in the values of the explanatory variables contained in $\mathbf{X}$ (Allison 2001).

Using maximum likelihood procedures to estimate the unknown parameter vector in equation (1) is inappropriate in this study because survey respondents within communities are nonindependent. Use of maximum likelihood estimation of (1) with such hierarchically structured data produces biased and inefficient regression coefficients and underestimates the standard errors (Guo and Zhang 2000). To overcome the problems arising from hierarchal nesting, I estimated (1) with the full penalized quasi-likelihood methods (PQL) implemented in the software Hierarchical General Linear Model (HGLM) (Bryk, Raudenbush, and Congdon 1996). HGLM reformulates (1) as two systems of equations. The first system or the microlevel system of equations has the same form as (1) but includes only the individual-level variables as predictors and is estimated for each of the 63 communities in the study sample. A second or macrolevel system of equations treats the intercepts from the microlevel system as dependent functionally on the community level variables and a normally distributed random error term with mean zero and unknown variance. The error term in the second level system represents the unique effect of belonging to a community. By explicitly modeling this error, HGLM controls for community-level sources of nonindependence.

One problem with HGLM is that, in the absence of a closed form for the multinomial logit's likelihood function when data are nested hierarchically, it obtains estimates of the unknown regression parameters and their standard errors by maximizing a Taylor series approximation (Bryk et al. 1996). Simulation studies have revealed that using an approximation to the likelihood function downwardly biases estimates of the standard errors. This bias can be quite large for data sets with very large numbers of clusters, many clusters with very few observations, and high intracluster correlations (or proportions of the total variance in the dependent variable accounted for by the community-level units) (Guo and Zhao 2000). 
For this study, estimation bias associated with PQL is unlikely to be substantial. The study has a moderate number of moderate size clusters with between 18 to 57 observations. The average cluster size is about 29 . No cluster had only one observation. Intracluster correlations are on the low side for all the dependent variables and range from a minimum of $2.8 \%$ for the desire to the space (SPACE) versus having a child (NOW) dependent variable to a maximum of about $11.6 \%$ for the traditional contraception (TRAD) versus no contraception (NOT) variable. ${ }^{2}$ To further reduce the chances of underestimated standard errors leading to erroneous conclusions, I based interpretation of the multivariate results only on coefficients that met the 5\% significance test.

\subsection{Multivariate results}

The estimated logit coefficients for this analysis are presented in tables 2 and 3. Along with the logits, two other types of coefficients, odds ratios and intercept component variances, are reported. The odds ratios, in parentheses, help clarify the magnitudes of the predictor effects. The ratios are standardized for continuous variables and show changes in the odds of making choices on the outcome variable in response to increases by one standard deviation in the values of the predictor variables. Ratios reported for categorical and binary independent variables reveal changes in the odds of choices on the outcome variable in response to unit shifts in values of the predictor variables (Long 1997). Estimates of intercept variances presented in the lower parts of the tables show the residual variation in the outcome variables associated with community residence after variance attributable to the model variables is removed.

\subsubsection{Interest in regulating fertility}

The analysis for women's interest in fertility regulation produced the two equations in table 2 for the determinants of limiting (LIMIT) or spacing (SPACE) childbearing versus having children at the time of the survey (NOW).

2 According to Hedeker (2003), the intra-cluster correlation in logistic regression models containing only a random intercept is $\mathrm{r}_{\mathrm{it}}=\mathrm{intercept}$ variance/(intercept variance + level-one variance). The level-one variance is set equal to 3.29 , the variance of a logistic distribution. The other term is the level-two variance corresponding to the intercept of the Tth category of the dependent variable. 
Benefo: The community-level effects of women's education on reproductive behavior in rural Ghana

\section{Table 2: Multinomial logit coefficients for women's interest in fertility regulation: 1988, rural Ghana}

\begin{tabular}{|c|c|c|}
\hline Variables & LIMIT v. NOW & SPACE V. NOW \\
\hline Intercept & $-4.777^{\star \star *}$ & $1.749^{* \star \star}$ \\
\hline \multicolumn{3}{|l|}{ Individual-Level Variables } \\
\hline \multirow[t]{2}{*}{ Woman's exposure to family planning ads. } & $0.768^{* * *}$ & 0,307 \\
\hline & $(2.155)^{2}$ & $(1.359)$ \\
\hline \multirow[t]{2}{*}{ Woman's schooling } & $0.438^{* *}$ & 0,197 \\
\hline & $(1.550)$ & $(1.218)$ \\
\hline \multirow[t]{2}{*}{ Woman's work } & $-0.299^{* *}$ & $-0.266^{\star *}$ \\
\hline & $(0.742)$ & $(0.742)$ \\
\hline \multirow[t]{2}{*}{ Woman's Gaadangbe-ewe ethnicity } & $0.831^{* \star *}$ & 0,042 \\
\hline & (2.296) & $(1.043)$ \\
\hline \multirow[t]{2}{*}{ Woman's non-animist religion } & -0.253 & $-0.647^{\star * *}$ \\
\hline & $(0.776)$ & $(0.524)$ \\
\hline \multirow[t]{2}{*}{ Woman's age at 1 st marriage } & $-0,011$ & $0.115^{\star \star \star}$ \\
\hline & $(0.964)$ & $(1.467)$ \\
\hline \multirow[t]{2}{*}{ Woman's age } & $-0,011$ & $-0.17^{\star \star *}$ \\
\hline & $(0.913)$ & $(0.247)$ \\
\hline \multirow[t]{2}{*}{ Woman's surviving children } & $0.711^{* * *}$ & $0.425^{* * *}$ \\
\hline & $(5.059)$ & $(2.635)$ \\
\hline \multicolumn{3}{|l|}{ Community-Level Variables } \\
\hline \multirow[t]{2}{*}{ Aggregate women's education } & $0.023^{\star * *}$ & $-0,001$ \\
\hline & $(1.760)$ & $(0.976)$ \\
\hline \multirow[t]{2}{*}{ Urbanization } & 0,009 & $0.016^{\star \star *}$ \\
\hline & $(1.118)$ & $(1.219)$ \\
\hline \multirow[t]{2}{*}{ Public transportation } & 0,109 & 0,086 \\
\hline & $(1.115)$ & $(1.090)$ \\
\hline \multirow[t]{2}{*}{ Motorable road only } & $0.875^{\star \star *}$ & $0.479^{* \star *}$ \\
\hline & (2.399) & $(1.614)$ \\
\hline \multirow[t]{2}{*}{ Community infrastructure development } & $-0,027$ & 0,018 \\
\hline & $(0.904)$ & $(1.070)$ \\
\hline Intercept variance component & 0,186 & 0,063 \\
\hline Chi square statistic (df) & $1549.95(57)^{\star \star *}$ & $839.34(57)^{* * *}$ \\
\hline Individual Sample Size & 1812 & 1812 \\
\hline Community Sample Size & 63 & 63 \\
\hline
\end{tabular}

${ }^{* *} \mathrm{p}<.05 ;{ }^{* * *} \mathrm{p}<.01$

${ }^{1}$ Equation is a random error coefficient model estimated with HGLM.

${ }^{2}$ Odds ratios 
Interest in limiting family size is revealed to differ from interest in spacing in its relationship with individual socio-economic status and life-cycle stage. The desire to limit childbearing increases with socio-economic status but is only weakly related to life-cycle stage. Three of the socio-economic variables - a woman's own education, her Gaadangbe-Ewe ethnicity and her exposure to family planning commercials - have significant and positive effects in the LIMIT equation, whereas family size is the only one of the three life-cycle variables that is significant. Unlike limiting, interest in spacing does not increase with socio-economic status but has strong associations with life-cycle stage. A woman's education, her Gaadangbe-ewe ethnicity and her exposure to family planning commercials have no effects on her interest in spacing. The two significant socio-economic status variables both indicate that high status decreases a woman's interest in spacing. Non-animists and nonfamily workers are less likely than others to express an interest in spacing, not more likely. On the other hand, all three life-cycle variables, family size, age and age at first marriage, have significant effects on interest in spacing.

Although individual-level characteristics are shown to be important, table 2 reveals that community characteristics also influence whether a woman will be interested in regulating her fertility. The highly significant estimates of the intercept variance show that there remain community-level variables not included in this study that shape a woman's interest in regulating her childbearing. Furthermore, several of the community characteristics included in the study are highly significant determinants of women's interest in regulating their fertility. The aggregate education of women is shown to increase women's interest in limiting their fertility but has no effect on their desire to space. The odds ratios reveal aggregate women's education to have an impact on interest in limiting fertility that is comparable in magnitude to its individual-level counterpart. A standard deviation increase in the percent of women in a community with education increases the odds that a woman will be interested in limiting her fertility by $76 \%$. The education of a single woman increases her odds of being interested in limiting fertility by only $55 \%$.

Community access to transportation influences women's interest in regulating childbearing but the effect is complicated. Community access to motorable roads stands out as increasing interest in both limiting and spacing childbirths. But communities with access to public transportation, which presumably are the best endowed with communication resources, are no different at all from those with no access to any motorable roads. The effect of motorable road access on women's interest in limiting their childbearing is quite substantial and even exceeds that of aggregate education in magnitude. Compared to other women, those in communities with motorable roads have $139 \%$ higher odds of being interested in limiting and only $61 \%$ higher odds of being interested in spacing their childbearing. Proximity to an urban area increases 
interest in spacing but has no effect on interest in limiting childbearing. The community infrastructural development is never significant.

The results reported in this sub-section show that a woman's interest in regulating her fertility is affected by the education of other women in her community. It also reveals other community influences operating alongside the education of other women. In the next section, I examine whether aggregate women's education and the other community characteristics are determinants of contraception.

\subsubsection{Contraceptive use}

Equations for the contrasts between the three groups of women interested in contraception (MODERN, TRAD and INTEND) with those not interested (NOT) are presented in the first three columns of Table 3. The multivariate results reveal the usefulness of distinguishing contraception by type. The effects of the individual-level controls are found to differ between modern and traditional contraception. The results in the first column show that modern contraception increases with socioeconomic status but has a weak relationship with life-cycle stage. A woman's exposure to family planning commercials, her education and nonfamily work all have highly significant and positive effects in the MODERN equation, whereas from among the life-cycle variables only her family size is significant. In contrast, results in the second column show socio-economic status has a weaker relationship with traditional contraception than with modern contraception. The coefficients for family planning exposure and nonfamily work are positive but much smaller in the traditional contraception equation than in the modern methods equation. Non-animism's negative effect in the second column also means that traditional contraception is quite high among some low status social groups. Lastly, unlike modern contraception, traditional contraception is strongly related with life-cycle stage. Family size, age at marriage and age, all have significant coefficients.

Once again, the highly significant intercept variances indicate that communitylevel variables not included in this study can explain variance in contraception. Several of the community characteristics included are shown to be important determinants of modern and traditional contraception. Aggregate women's education has a positive and significant effect in the modern contraception equation but not in the traditional contraception equation. The odds ratios reveal aggregate education has an impact on modern contraceptive use that is comparable in magnitude to the effect of its individuallevel counterpart. A standard deviation increase in the percent of educated women in a cluster increases a woman's odds of using modern contraception by over $80 \%$ (odds 
ratio of 1.79) whereas educating a woman raises her odds of using modern contraception by $114 \%$ (odds ratio of 2.14 ).

Table 3: Multinomial logit coefficients for women's contraceptive use: 1988, rural Ghana

\begin{tabular}{|c|c|c|c|}
\hline & MODERN v. NONUSE & TRAD v. NONUSE & INTEND v. NONUSE \\
\hline Intercept & $-5.953^{\star \star *}$ & $-4.373^{\star \star *}$ & $-1.017^{\star \star *}$ \\
\hline \multicolumn{4}{|l|}{ Individual-Level Variables } \\
\hline \multirow[t]{2}{*}{ Woman's exposure to family planning ads. } & $2.428^{\star \star \star}$ & $1.417^{\star \star *}$ & $1.054^{\star \star *}$ \\
\hline & $(11.336)^{2}$ & $(4.125)$ & $(2.869)$ \\
\hline \multirow[t]{2}{*}{ Woman's schooling } & $0.761^{* *}$ & $0.912^{\star \star *}$ & $0.568^{* \star *}$ \\
\hline & $(2.140)$ & $(2.489)$ & $(1.765)$ \\
\hline \multirow[t]{2}{*}{ Woman's work } & $0.742^{\star *}$ & 0,472 & 0,098 \\
\hline & $(2.100)$ & $(1.603)$ & $(1.103)$ \\
\hline \multirow[t]{2}{*}{ Woman's Gaadangbe-ewe ethnicity } & $-0,568$ & 0,195 & 0,182 \\
\hline & $(0.567)$ & $(1.215)$ & $(1.200)$ \\
\hline \multirow[t]{2}{*}{ Woman's non-animist religion } & 0.365 & $-0.821^{* * *}$ & 0,161 \\
\hline & $(1.441)$ & $(0.440)$ & $(1.175)$ \\
\hline \multirow[t]{2}{*}{ Woman's age at 1 st marriage } & $-0,024$ & $0.114^{\star *}$ & $0.052^{* * *}$ \\
\hline & $(0.923)$ & $(1.462)$ & $(1.189)$ \\
\hline \multirow[t]{2}{*}{ Woman's age } & $-0,013$ & $-0.097^{\star * *}$ & $-0.104^{* * *}$ \\
\hline & $(0.895)$ & $(0.450)$ & $(0.425)$ \\
\hline \multirow[t]{2}{*}{ Woman's surviving children } & $0.282^{\star *}$ & $0.436^{\star * *}$ & $0.409^{* \star *}$ \\
\hline & $(1.902)$ & $(2.702)$ & $(2.541)$ \\
\hline \multicolumn{4}{|l|}{ Community-Level Variables } \\
\hline \multirow[t]{2}{*}{ Aggregate women's education } & $0.024^{* * *}$ & $-0,012$ & 0,007 \\
\hline & $(1.804)$ & $(0.744)$ & $(1.188)$ \\
\hline \multirow[t]{2}{*}{ Urbanization } & $-0,002$ & $0.023^{\star \star *}$ & 0,005 \\
\hline & $(0.976)$ & $(1.330)$ & $(1.064)$ \\
\hline \multirow[t]{2}{*}{ Public transport } & 0,46 & $0.736^{\star *}$ & 0,305 \\
\hline & $(0.976)$ & $(2.088)$ & $(1.357)$ \\
\hline \multirow[t]{2}{*}{ Motorable road only } & $1.047^{* *}$ & 0,03 & 0,084 \\
\hline & $(2.849)$ & $(1.030)$ & $(1.088)$ \\
\hline \multirow[t]{2}{*}{ Community infrastructure development } & $-0,027$ & 0,024 & 0,01 \\
\hline & $(0.904)$ & $(1.094)$ & $(1.038)$ \\
\hline Intercept variance component & 0,203 & 0,389 & 0,145 \\
\hline Chi square statistic (df) & $236.7(57)^{\star \star \star}$ & $440.13(57)^{\star \star \star}$ & $123.55(57)^{\star \star \star}$ \\
\hline Individual sample size & 1812 & 1812 & 1812 \\
\hline Community sample size & 63 & 63 & 63 \\
\hline
\end{tabular}


Community access to transportation is associated with contraceptive use but as in the preceding section on women's interest in regulating fertility, this effect is observed to be very complicated. Community access to public transportation has a significant positive effect only on traditional contraception while community access to motorable roads has a positive and significant effect in the modern contraception equation. As before, the effect that community access to a motorable road has on modern contraception is shown to be quite large. Such access increases the odds of modern contraceptive use by $185 \%$ (unit odds ratio of 2.849). District urbanization has a positive effect in the traditional methods equation only while the community-level infrastructural development variable has no significant effects.

In the third column of table 3 , the individual-level life cycle and socio-economic status variables have roughly the same effects on intention to use contraception as they have for actual contraceptive use. The intercept variance is also highly significant to indicate that community-level variables not included in this study can explain variance in intention to use contraception. However, unlike in the case for actual contraception, none of the community-level effects included in the study is significant in the third column. A possible reason for this is that people who intend to use contraception include both those intending to use modern methods and those intending to use traditional contraception. Since the two method types respond differently to community characteristics, pooling the two groups could have reduced the community effects.

\section{Discussion and conclusion}

This study finds that a woman's socio-economic status as well as her life cycle stage affect her reproductive behavior. This relationship is quite complicated and varies depending on the aspect of reproductive behavior examined. For instance, women's interest in limiting childbearing and using modern contraception increases with her socioeconomic status. In contrast, a woman's interest in spacing and traditional contraception is found to be influenced largely by her life cycle stage. As demographers believe that limiting fertility and using modern contraception are the critical behavioral ingredients for initiating and sustaining modern day fertility declines, this finding suggests that improving women's socio-economic status will promote that transformation.

Although finding that women's individual-level socio-economic mobility increases their interest in regulating fertility and using contraception is important, this study's most significant contribution is to show that community characteristics shape fertilityrelated decisions. One important community characteristic is the presence of educated women in a community. The study finds that as the percent of educated women 
increases in a community, women, regardless of their individual characteristics, become more interested in limiting childbearing and using modern contraception. This effect is very large relative to the effects obtained by educating a single woman and suggests that educating women elicits reductions in fertility for all women, regardless of their individual socio-economic status. Moreover, the study finds no evidence that aggregate women's education reduces interest in spacing and none that it reduces traditional contraception. There is therefore no evidence that aggregate education of women has the potential to increase fertility by eroding older methods of fertility regulation.

Community access to transportation also increases women's interest in regulating fertility and affects their use of contraception. But the effect is complex and does not clearly show that improved transportation supports reproductive innovation. Women with the best access to communication facilities in communities with public transportation are no different in terms of their interest in limiting fertility and in their use of modern contraception than those in places with no access to transportation. It is women in communities with access to motorable transportation who are much more likely than other women to be interested in limiting fertility and using modern contraception.

The transportation effect observed in this study defies easy interpretation. It is possible that limited mobility in communities with only motorable roads restricts external cultural contacts to socio-economic elites. Ideational inputs entering such communities are then relatively elitist and thus support women's interest in limiting fertility and using modern contraceptives. In contrast to the experience of communities with only motorable roads, external cultural contacts in communities with public transportation may be less selective by socio-economic privilege. Ideational inputs arriving in such communities are therefore diverse and provide exposure to reproductive ideas and behavior common to lower status people. Women in such communities thus end up finding more social support for using traditional contraceptives than their counterparts in places with only motorable roads.

Proximity to urban areas is a source of reproductive change in these rural communities, but it is not as powerful as women's education. In this setting, urbanization increases rural women's interest in spacing children and using traditional contraception but has no effects on their interest in limiting children and using modern contraception. One possible explanation for those findings is that lower status migrants provide the conduit for reproductive ideas developed in urban areas to diffuse to rural areas. The ideas that diffuse are those that support spacing children and traditional contraception.

That there is absolutely no association between community infrastructural development and reproductive behavior casts doubt on the developmentalist perspective that rural economic development is required to lift welfare sufficiently before fertility 
can be expected to decline. It does not seem to be necessary that the economic cost of childbearing or that uncertainties and risk of rural life should decrease substantially before people become interested in regulating fertility or using contraception in this setting.

The community-level characteristics included in the statistical models that turned out to be significant allowed us to pinpoint some of the important community influences on fertility in rural Ghana. The highly significant intercept variances also showed that a great deal of the variation in women's interest in fertility regulation remained to be explained by characteristics of communities, even after accounting for the effects of predictors used in the analyses. More work remains to be done examining the role of community-level characteristics in shaping fertility-related behavior in rural Ghana. 


\section{References}

Ahmed, R. 1994. "Investment in rural infrastructure: critical for commercialization." Pp. 141-152 in Agricultural Commercialization, Economic Development, and Nutrition, edited by J. v. Braun and E. Kennedy. Baltimore: John Hopkins Press.

Allison, Paul D. 1999. Logistic Regression: Using the SAS System: Theory and Application. Cary, NC: SAS Institute Inc.

Amin, S., I. Diamond, and F. Steele. 1996. "Contraception and religious practice in Bangladesh." Pp. 268-89 in The Continuing Demographic Transition, edited by G. W. Jones, R. M. Douglas, J. C. Caldwell, and R. M. D'Souza. Oxford, England: Clarendon Press.

Bankole, A., German Rodriguez, and Charles F. Westoff. 1996. "Mass media messages and reproductive behavior in Nigeria." Journal of Biosocial Science 28:227 239.

Bleek, Wolf. 1987. "Family and family planning in southern Ghana." Pp. 138-153 in Sex Roles, Population and Development in West Africa, edited by C. Oppong. Portsmouth, N.H.: Heinemann.

Brockerhoff, Martin. 1995. " Fertility and family planning in African cities: The impact of female migration." Journal of Biosocial Science 27:347-358.

Bryk, Anthony, Stephen Raudenbush, and Richard Congdon. 1996. Hierarchical Linear and Nonlinear Modeling with the HLM/2L and HLM/3L Programs. Chicago: SSI Scientific Software International.

Caldwell, J. and Pat Caldwell. 1985. "Cultural forces tending to sustain high fertility in tropical Africa." World Bank, Washington, D.C. PHN Technical Note 85-16.

Easterlin, R. A. and Eeileen M. Crimmins. 1985. The Fertility Revolution: A Supply and Demand Analysis. Chicago: The University of Chicago Press.

Entwisle, Barbara, John B. Casterline, and Hussein A.-A. Sayed. 1989. "Villages as contexts for contraceptive behavior in rural Egypt." American Soiological Review 54:1019-1034.

Freedman, Ronald. 1997. "Do family planning programs affect fertility preferences?" Studies in Family Planning 28:1-13.

Ghana, Government of. 1984. 1984 Population Census of Ghana. Accra: Ghana Statistical Service. 
—. 1987. Ghana Living Standards Survey. Ghana Statistical Service, Accra.

—. 1988. The Ghana Living Standard Survey. Ghana Statistical Service, Accra.

Goldscheider, Calvin. 1984. "Migration and rural fertility in less developed countries." Pp. 34-48 in Rural Development and Human Fertility., edited by W. A. Schutjer and C. S. Stokes. New York NY: Macmillan.

Gugler, J and WG Flanagan. 1978. Urbanization and Social Change in West Africa. Cambridge; New York: Cambridge University Press.

Guo, G and H Zhao. 2000. "Multilevel modeling for binary data." Annual Review of Sociology 26:441-62.

Gustavo, Angeles, David K. Guilkey, and Thomas A. Mroz. 1988. "Purposive program placement and the estimation of family planning program effects in Tanzania." Journal of the American Statistical Association 93:884 - 899.

Hammerslough, Charles. 1992. "Proximity to contraceptive services and fertility transition in rural Kenya." International Family Planning Perspectives 18:54 58.

Harbison, Sarah F. and Warren C. Robinson. 1985. "Rural electrification and fertility change." Population Research and Policy Review 4:149 - 171.

Health, Ghana Ministry of. 1992. "Conceptions and misconceptions: community views of family planning." Health Research Unit, Accra, Ghana. Unpublished.

Hedeker, Donald. 2003. "A mixed-effects multinomial logistic regression model." Statistics in Medicine 22:1433-1446.

Hirschman, C. and P. Guest. 1990. "Multilevel models of fertility determination in four southeast Asian countries: 1970 and 1980." Demography 27:369-396.

Hirschman, Charles. 1985. "Premarital socioeconomic roles and the timing of family formation: A comparative study of five Asian Societies." Demography 22:35-59.

Hirschman, Charles and Yih-Jin Young. 2000. "Social context and fertility decline in Southeast Asia.." Pp. 11-39 in Population and Economic Change in East Asia, vol. A supplement to Vol. 26 Population and Development Review., edited by R. D. Lee and C. Y. C. Chu.

Johnson-Hanks, Jennifer. 2003. "Education, ethnicity, and reproductive practice in Cameroon." Population-E 58:1-27. 
Kocher, James E. 1979. "Rural Development and Fertility Change in Tropical Africa: Evidence from Tanzania." Michigan State University, East Lansing. African Rural Economy Paper, no.19.

Kravdal, Øystein. 2000. "A search for aggregate-Level effects of education on fertility, using data from Zimbabwe." Demographic Research 3.

-. 2002. "Education and fertility in sub-Saharan Africa: Individual and community effects." Demography 39:233-250.

Lesthaeghe, R. 1984. "Fertility and its proximate determinants in sub-Saharan Africa: the record of the 1960s and 1970s." IVrije Universiteit Interuniversity Program in Demography Working Paper 1984-2, Brussels.

Lesthaeghe, R., C. Vanderhoeft, S. Becker, and M. Kibet. 1985. "Individual and contextual effects of education on proximate fertility determinants and on lifetime fertility in Kenya." Pp. 31-63 in The Collection and Analysis of Community Data., edited by J. B.Casterline. Voorburg, Netherlands: International Statistical Institute.

Lloyd, Cynthia B., Carol E. Kaufman, and Paul Hewet. 2000. "The Spread of Primary Schooing in Sub-Saharan Africa: Implications for Fertility Change." Population and Development Review 26:483 - 515.

Long, Scott J. 1997. Regression Models for Categorical and Limited Dependent Variables. Thousand Oaks: Sage Publications.

Maddala, G. S. 1983. Limited - Dependent and Qualitative Variables in Economics. Cambridge: Cambridge University Press.

Malhotra, Anju and Shyam Thapa. 1991. "Determinants of contraceptive method choice in Sri Lanka: An update of a 1987 survey." Asia-Pacific Population Journal 6:25-40.

Mason, K. O. 1987. "The impact of women's social position on fertility in developing countries." Sociological Forum 2: 718-745.

McNay, Kirsty, Perianayagam Arokiasamy, and Robert H. Cassen. 2003. "Why are uneducated women in India using contraception? A multilevel analysis." Population Studies 57:21-40.

Montgomery, M. R. and J. B. Casterline. 1996. "Social learning, social influence and new models of fertility." Population and Development Review 22:151-175. 
Moursund, Anne and Øystein Kravdal. 2003. "Individual and community effects of women's education and autonomy on contraceptive use in India." Population Studies 57:285 - 301.

Nations, United. 1991. World Population Prospects 1990. Department of International Economic and Social Affairs, New York.

Onuoha, Nelson C. and Ian M. Timaeus. 1995. "Has a fertility transition begun in West Africa?" Journal of International Development 7:93 - 116.

Raftery, Adrian E., Steven M. Lewis, and Akbar Aghajanian. 1995. "Demand or ideation? Evidence from Iranian marital fertility decline." Demography 32:159 182.

Raudenbush, S. W. and A. S. Bryk. 2002. Hierarchical Linear Models. Thousand Oaks, Calif.: Sage.

Reed, Holly, Rona Briere, and John Casterline. 1999. The Role of Diffusion Processes in Fertility Change in Developing Countries: Report of A Workshop. Committee on Population, National Research Council, Washington D.C.

Saha, Tulshi D. 1994. "Community resources and reproductive behaviour in rural Bangladesh." Asia-Pacific Population Journal 9:3 - 18.

Service, Ghana Statistical. 1989. Ghana Demographic and Health Survey 1988. Columbia, Maryland: IRD/Macro Systems, Inc.

Shapiro, David and B. Oleko Tambashe. 2001. "Fertility Transition in Urban and Rural Areas of Sub-Saharan Africa." Population Research Institute, The Pennsylvania State University, University Park, PA.

Tienda, M., V. G. Diaz, and S. A. Smith.. 1985. "Community education and differential fertility in Peru." Canadian Studies in Population 12:137-158.

Van de Walle, Etienne and John Knodel. 1980. "Europe's fertility transition: New evidence and lessons for today's developing world." Population Reference Bureau. Population Bulletin 34(6).

Watkins, Susan Cotts. 1991. "More Lessons from the Past: Women's Informal Networks and Fertility Decline." in Seminar on the Course of Fertility Transition in sub-Saharan Africa. Harare, Zimbabwe: International Union for the Scientific Study of Population. 
Westoff, Charles. 1999. "Mass communications and fertility." Pp. 237 - 251 in Dynamics of Values in Fertility Change, edited by R. Leete. Oxford: Oxford University press.

Westoff, Charles. and German. Rodriguez. 1995. "The mass media and family planning in Kenya." International Family Planning Perspectives 21:26 - 31. 
Benefo: The community-level effects of women's education on reproductive behavior in rural Ghana 